\title{
Ion-plasma nitriding of disc saws of the fiber-extracting machine
}

\author{
Akbar Abrorov*, Matluba Kuvoncheva, Mukhsin Mukhammadov \\ Bukhara Engineering Technological Institute, Bukhara, Uzbekistan \\ *E-mail: abrorov1975@mail.ru
}

\begin{abstract}
The technology of deep ion-plasma nitriding has been developed in this article and its practical implementation for disc saws made of U8G steel has been carried out. The technology of deep ion-plasma nitriding was implemented on the STANKIN-APP-1 installation. A circular saw made of U8G steel and witness samples of the same steel were selected as the object of research for subsequent measurement of microhardness and phase analysis. In order to avoid deformation of the saw blade, a tooling was developed, since the thickness of the saw blade is $0.95 \mathrm{~mm}$. The results of resistance tests have shown the feasibility of using this technology for disc saws. The total resistance of the teeth of disc circular saw made of U8G steel increased by 4 times compared to a circular saw without nitriding.
\end{abstract}

Keywords: ion-plasma nitriding, disc saw, U8G steel, fiber-extracting machine 


\title{
Ионно-плазменное азотирование дисковых пил волокноотделительной машины
}

\author{
Акбар Аброров, Матлуба Кувончева, Мухсин Мухаммадов \\ Бухарский инженерно-технологический институт, Бухара, Узбекистан \\ E-mail: abrorov1975@mail.ru
}

\begin{abstract}
Аннотация. В данной статье разработана технология глубокого ионно-плазменного азотирования и произведена ее практическая реализация для дисковых пил из стали У8Г. Реализация технологии глубокого ионно-плазменного азотирования выполнена на установке "СТАНКИН-АПП-1". В качестве объекта исследования была выбрана дисковая пила из стали У8Г и образцы-свидетели той же стали для последующего измерения микротвердости и фазового анализа. Во избежание деформации дисковой пилы была разработана оснастка, так как толщина дисковой пилы составляет 0,95 мм. Результаты стойкостных испытаний показали целесообразность применения данной технологии для дисковых пил. Суммарная стойкость зубьев дисковой пилы из стали У8Г увеличилась в 4 раза по сравнению с дисковой пилы без азотирования.
\end{abstract}

Ключевые слова: ионно-плазменное азотирование, дисковая пила, сталь У8Г, волокноотделительная машина

\section{1. Введение}

Задача повышения эффективности дисковой пилы узла пильного цилиндра волокноотделительной машины путем увеличения стойкости зуба может быть решена за счет применения ионно-плазменного азотирования. Эта технология позволяет значительно ускорить процесс насыщения поверхности зуба азотом по сравнению с традиционным печным азотированием. Так при азотировании дисковой пилы узла пильного цилиндра волокноотделительной машины углеродистой стали У8Г, 65Г в плазме двухступенчатого вакуумно-дугового разряда (ДВДР) в течение одного часа образуется слой с эффективной толщиной до 100 мкм и твердостью до 11,8 ГПа [1]. Стойкость зуба дисковой пилы, прошедшего такую обработку, возрастает в 1,5-2,5 раза по сравнению с неазотированным дисковой пилой [2].

Однако, толщина получаемого азотированного слоя не позволяет повысить суммарную стойкость дисковой пилы, так как после первой же переточки удаляется упрочненный азотированный слой. Получить глубокий азотированный слой возможно за счет увеличения времени азотирования до нескольких десятков часов, но при длительном тепловом 
воздействии происходит разупрочнение дисковой пилы. Таким образом, получение глубоких азотированных слоев (более 2 мм) на готовой дисковой пиле, используя только технологию ДВДР, невозможно.

\section{2. Метод}

Одним из решений данной задачи может быть применение технологии глубокого азотирования, суть которой заключается в том, что ионно-плазменное азотирование по методу ДВДР выполняется до окончательной термической обработки.

Предложенная технология выгодно отличается от других известных технологий азотирования дисковой пилы тем, что в стали создается относительно глубокий диффузионный слой с высокой концентрацией азота. В ходе проведения последующей закалки дисковой пилы азот диффундирует вглубь изделия, повышая твердость и теплостойкость стали на глубине до 2-2,5 мм.

Метод ионно-плазменного азотирования по методу ДВДР позволяет за счет высокой эмиссионной способности плазмы обеспечить очистку, нагрев и высокую скорость диффузии азота вглубь металла [3]. Благодаря такому решению за короткое время (0,5-2 часа) в тонком (до 200 мкм) поверхностном слое удается достичь высокой концентрации азота. Это является необходимым условием получения глубоких азотированных слоев в стали после того, как дисковая пила пройдет окончательную термическую обработку, стандартную для выбранной марки стали.

\section{3. Методика эксперимента}

Реализация технологии глубокого ионно-плазменного азотирования осуществляли на установке "СТАНКИН-АПП-1". В качестве объекта исследования была выбрана дисковая пила из стали У8Г и образцы-свидетели той же стали для последующего измерения микротвердости и фазового анализа. Во избежание деформации дисковой пилы была разработана оснастка, так как толщина дисковой пилы составляет 0,95 мм (рисунок 1).

Дисковая пила и образцы после механической обработки отожженной стальной заготовки помещались в вакуумную камеру установки "СТАНКИН-АПП-1". Затем, осуществляли нагрев до $650{ }^{\circ} \mathrm{C}$ в среде аргона при давлении 0,4 Па с одновременной ионной очисткой поверхности. Ионно-плазменное азотирование проводилось при $650{ }^{\circ} \mathrm{C}$ в среде чистого азота в течение 1 ч при токе дуги Ід $=80$ А и токе дополнительного анода Iда $=75 \mathrm{~A}$, при этом на стол с деталью подавалось напряжение смещения $\mathrm{U}=-700 \mathrm{~B}$. 


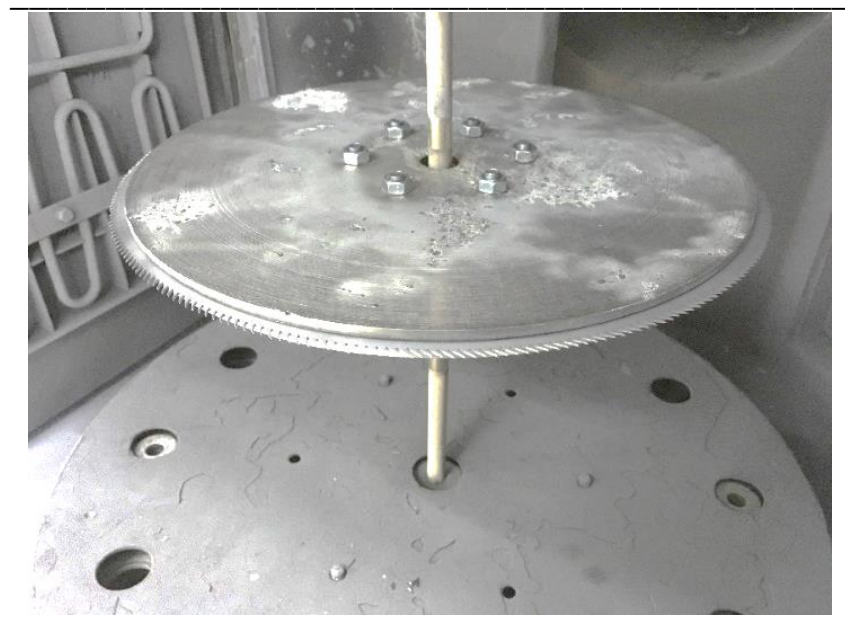

Рисунок 1. Дисковая пила с оснасткой, помещенная в вакуумную камеру установки "СТАНКИН-АПП-1".

После азотирования дисковая пила и образцы медленно охлаждались в камере до комнатной температуры. На заключительном этапе проводили стандартную термическую обработку:

- закалку с нагревом в соляной ванне в течение 4 мин при температуре $1220{ }^{\circ} \mathrm{C}$ и охлаждением в масле;

- трехкратный отпуск при $560^{\circ} \mathrm{C}$ по 1 ч.

Для измерения микротвердости и установления фазового состава изготавливали микрошлифы на оборудовании фирмы "Struers" (Дания).

Микротвердость измеряли с помощью приставки "Micro-duromat 4000" к микроскопу "Polyvar-Met" (Австрия) при нагрузке 0,294 Н и времени испытания 10 сек. Отпечатки на поверхность микрошлифа наносили в виде "дорожки" от края к центру с шагом от 10 до 200 мкм (в зависимости от твердости и расстояния от поверхности образца). При этом число отпечатков на каждой глубине варьировалось от трех до восьми в зависимости от величины разброса значений. Относительная ошибка среднего значения микротвердости с вероятностью 0,95 не превышала $4 \%$.

Рентгеновский фазовый анализ (РФА) проводили на дифрактометре PANalytical Empyrean (Голландия) с использованием $\mathrm{CuK \alpha -излучения.} \mathrm{Съемку} \mathrm{осуществляли} \mathrm{в} \mathrm{условиях}$ симметричной фокусировки по Брэггу-Брентано, с применением бета-фильтра.

Переточку выполняли на заточном станке с применением корундовых кругов. Глубина переточки по передней и задней поверхностям составила 0,8 и 0,2 мм, соответственно.

\section{4. Результаты эксперимента и их обсуждение}

Результаты измерения микротвердости после ионно-плазменного азотирования приведены на рисунок 2 и позволяют косвенно судить о высокой концентрации азота в тонком поверхностном слое. 


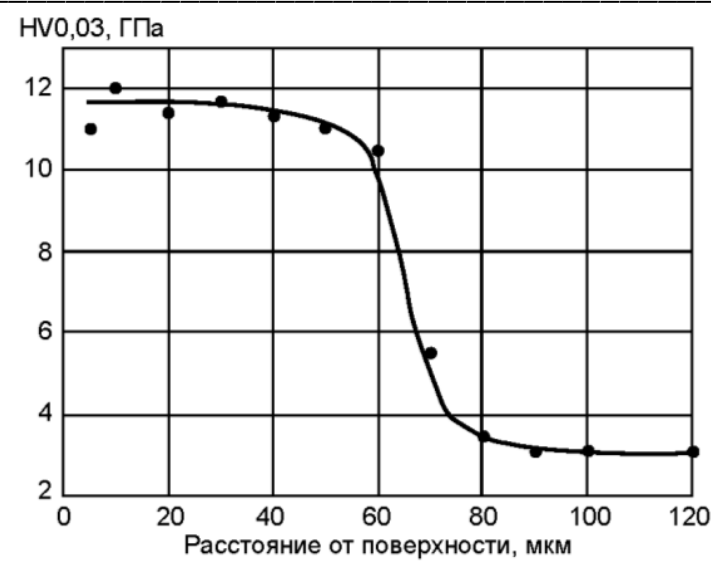

Рисунок 2. Распределение микротвердости по глубине в стали У8Г, прошедшей ионноплазменное азотирование при $650{ }^{\circ} \mathrm{C}$ c выдержкой 1 ч.

Об этом свидетельствует высокая микротвердость поверхностного слоя: на глубине до 60 мкм микротвердость составляет от 10 до 12 ГПа. Высокая твердость обусловлена присутствием в структуре стали сложных нитридов железа и легирующих компонентов типа $\mathrm{Me} 4 \mathrm{~N}$, которые содержат до $6 \%$ азота по массе, в то время как содержание азота в феррите существенно ниже (при $590^{\circ} \mathrm{C}$ не более $0,12 \%$ ) $[4,5]$. Созданная высокая концентрация азота в тонком приповерхностном слое необходима для дальнейшей диффузии азота вглубь стали в процессе последующей закалки.

При нагреве стали У8Г в соляной ванне под закалку $\left(1220^{\circ} \mathrm{C}\right)$ большая часть нитридов растворяются в аустените, а, следовательно, после закалки получается азотистый мартенсит, который обладает повышенной твердостью и теплостойкостью [6]. Результаты измерения микротвердости стали У8Г после закалки и трехкратного отпуска показали, что на глубине от 0,3 до 2 мм наблюдается твердость, значения которой выше, чем у основы стали (рисунок 3). Величина твердости на указанной глубине достигает 9,5 ГПа при твердости основы 8,9 ГПа.

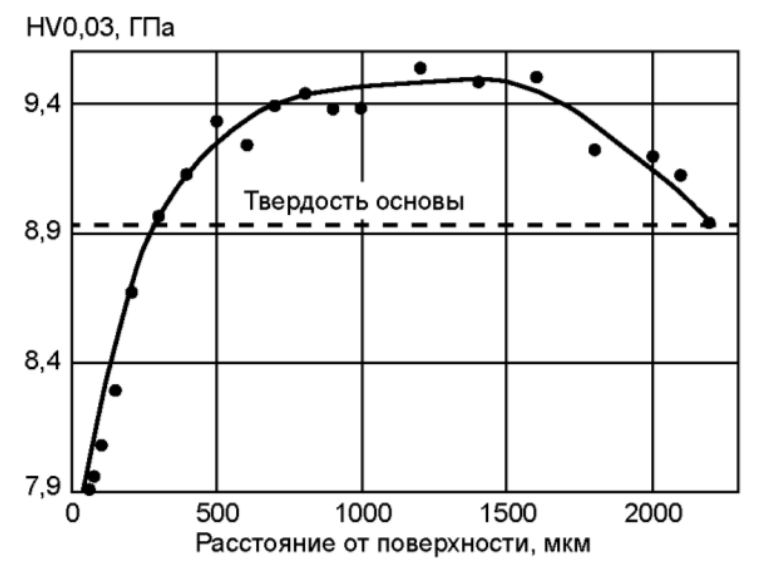

Рисунок 3. Распределение микротвердости по глубине в стали У8Г, прошедшей ионноплазменное азотирование при $650{ }^{\circ} \mathrm{C}$ с выдержкой 1 ч и последующую стандартную термическую обработку: закалку $1220{ }^{\circ} \mathrm{C}$ (масло) и трехкратный отпуск при $560{ }^{\circ} \mathrm{C}$ по 1 ч.

Диффузионный слой глубиной до 2 мм, по-видимому, образуется в ходе мартенситного превращения, а не при тепловой выдержке, так как за 4 мин при $1220{ }^{\circ} \mathrm{C}$ азот не может продиффундировать в аустените на глубину более 0,2 мм, согласно закону Фика. 
Высокие твердость и теплостойкость стали У8Г после проведенной обработки, а также большая глубина упрочненного слоя обуславливают повышенную стойкость зубьев дисковой пилы. Так, например, стойкость зубьев после глубокого азотирования в 2 раза выше по сравнению с неазотированными [7].

\section{5. Заключение}

В статье представлена разработанная технология глубокого ионно-плазменного азотирования и ее практическая реализация для дисковых пил из стали У8Г.

Показано, что технология глубокого азотирования позволяет получить глубину диффузионного слоя до 2 мм с повышенной твердостью и теплостойкостью, при этом сам процесс насыщения азотом не превышает 1 ч.

Результаты стойкостных испытаний показывают целесообразность применения данной технологии для дисковых пил. Суммарная стойкость зубьев дисковой пилы из стали У8Г увеличилась в 4 раза по сравнению со стойкостью зубьев дисковой пилы без азотирования.

\section{Список литературы}

[1] Abrorov, A. Method of thermal treatment of saw disk teeth of fiber-processing machines by laser quenching / A. Abrorov, M. Kuvoncheva, O. Rajabov, M. Mukhammadov, S. Jumaev // IOP Conference Series: Materials Science and Engineering. - 2020. - № 862. - 032034.

[2] Фукс-Рабинович, Г С. Износостойкость азотированного инструмента из быстрорежущих сталей / Г.С. Фукс-Рабинович, В.Ф. Моисеев, В.А. Брострем и др. // Трение и износ. 1995. - № 4. - С. 780-786.

[3] Urinov, N. Technology of ionic-plasmic nitriding of teeths of disc saw of the knot of saw cylinder / N. Urinov, M. Saidova, A. Abrorov, N. Kalandarov // IOP Conference Series: Materials Science and Engineering. - 2020. - № 734(1). - 012073.

[4] Федорович, В А. Азотирование и карбонитрирование / В.А. Федорович, А.В. Супов // Металлургия. - 1990. - С. 14-17.

[5] Лахтин, Ю.М. Азотирование стали / Ю.М. Лахтин, Я.Д. Коган // Машиностроение. - 976. - C. 257.

[6] Fedorov, S. Increasing the surface stability of the cutting tool through complex machining / S. Fedorov, J. Sharipov, A. Abrorov // Journal of Physics: Conference Series. - 2021. - № 1889(2). -022079.

[7] Богачёв, И И. Технология глубокого ионно-плазменного азотирования режущего инструмента / И.И. Богачёв, В.Н. Климов, С.В. Алешин // Станкостроение и инструментальное производство. - 2016. - № 5. - С. 30-32. 